\title{
Violência e Sociabilidade: A Formação do Estudante
}

Violence and Sociability: the Student's Formation

Entrar na Universidade é o sonho da maioria dos jovens, no entanto, quando o desejo torna-se realidade, o trote surge e pode representar agressões, violências e humilhações.

Segundo o dicionário Michaelis, um dos significados da palavra trote é "maneira de andar de cavalos e de outros quadrúpedes, entre o passo ordinário e o galope”. O animal precisa ser ensinado, muitas vezes à base de chicotadas, a caminhar mais rapidamente. Com origem na Idade Média, o trote universitário mantém a raiz etimológica da palavra, uma vez que reproduz a ideia de que o calouro precisa ser "domesticado" pelos veteranos ao espaço acadêmico que está sendo inserido.

Márcia Couto, professora do Departamento de Medicina Preventiva da FM-USP, entende que, apesar de características medievais persistirem no trote, há mudanças profundas que se agudizaram nas últimas décadas. "O trote não tem incorporado diferenciações e desigualdades latentes em nossa sociedade, como o reconhecimento da diversidade, do pluralismo de opiniões, de crenças e identidades. A universidade não acompanha essas mudanças; ela permanece fechada."

Uma das preocupações do calouro ao entrar na faculdade é, assim como de qualquer pessoa ao ser inserida em um novo grupo, o acolhimento. Por isso, o calouro mostra-se vulnerável aos veteranos que se sentem à vontade para imputar a ele inúmeras coerções, humilhações e violências de ordem física, emocional e psicológica. A partir desse contexto, estabelecem-se dois grupos: aqueles que acabam por aceitar o trote, por muitas vezes nem percebendo a situação como humilhante ou violenta, $\mathrm{e}$ aqueles que não aceitam a violência e sofrem represálias ao longo da graduação. Para o estudante da FM-USP e Coordenador de Cultura da Direção Executiva Nacional dos Estudantes de Medicina, Felipe Scalisa, "Quando os novos estudantes entram, acaba, naturalmente, existindo uma separação entre aqueles que vão se subordinar e aqueles que aceitam a própria exclusão." Ele também entende que o ingressante acredita que as novas leis que lhe estão sendo impostas são legítimas, principalmente
Gabriela SARMENTo

Universidade de São Paulo, Escola de Comunicações e Artes, São Paulo, Brasil 
Calouros dão barrigada na lama em trote da Escola

Politécnica. Foto:Julia Chequer

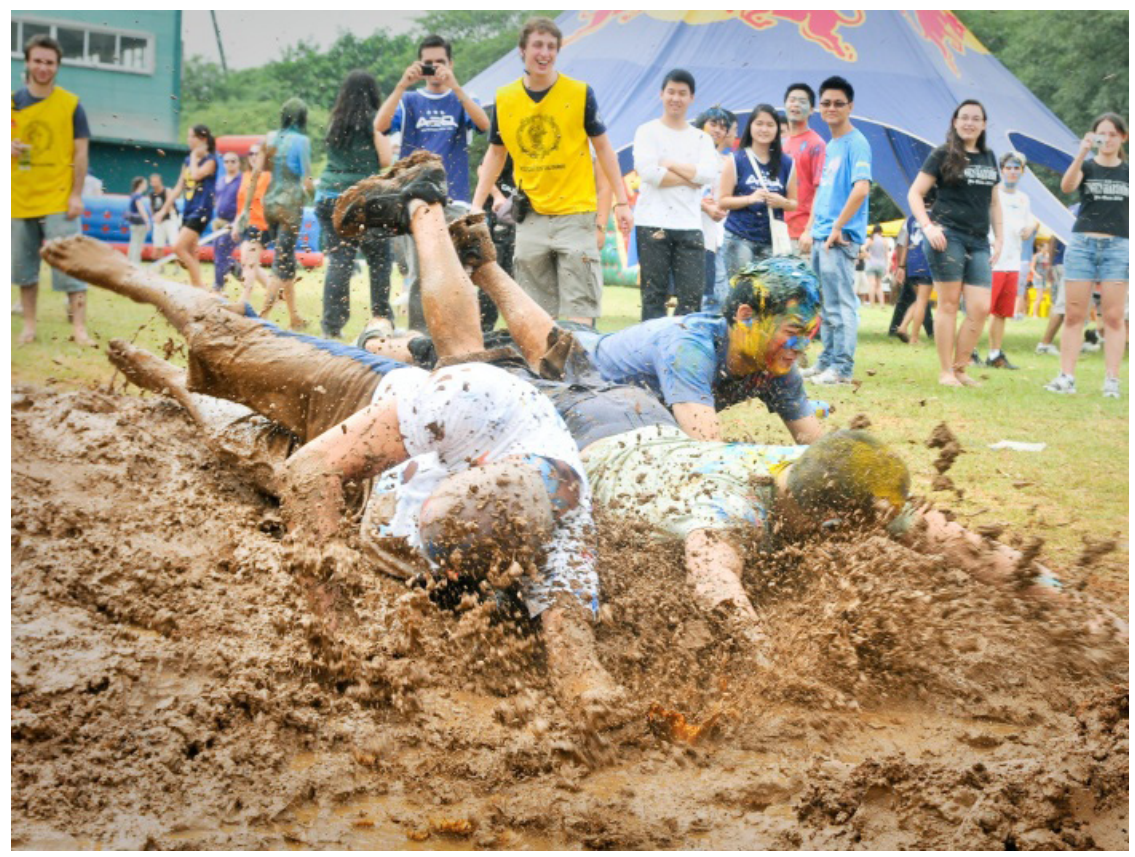

pelo tempo, uma vez que o termo "tradição" ganha um papel político muito importante nesses rituais.

A tradição é também o motivo que leva o veterano a perpetuar a violência contra os calouros. Mas, também segundo Scalisa, "há o mecanismo psicológico - até para aliviar um pouco o próprio trauma e a questão de se colocar na posição de poder." Márcia reafirma que a reprodução da violência é uma forma de manter fortemente delimitada a hierarquia entre os alunos, estabelecendo dessa forma um ciclo interminável.

Maria Fernanda Peres, também professora do Departamento de Medicina Preventiva e pesquisadora do Núcleo de Estudos da Violência, mediu a ocorrência de violência entre alunos do curso de Medicina, no projeto QUARA - Qualidade das relações no ambiente acadêmico e seu impacto na saúde mental e na qualidade de vida de estudantes de medicina: um estudo com corte transversal. $\mathrm{O}$ recorte do estudo recai sobre situações corriqueiras de violência, e não inclui apenas o trote, mas também outros episódios que acontecem durante a graduação. Entre os 317 alunos que responderam voluntariamente ao questionário, $90 \%$ sofreu pelo menos um tipo de agressão ao longo do curso, seja humilhação, depreciação, assédio, discriminação sexual, violência psicológica, física, verbal e psicológica acadêmica. Segundo a pesquisadora, "há uma extensa literatura internacional que mostra que no curso de Medicina, é extremamente frequente a ocorrência de situações de violência. Estudos feitos em cursos nos Estados Unidos e Alemanha mostram números semelhantes, com percentuais em torno de $80 \%$ e $90 \%$. A pesquisadora ressalva que pode existir uma superestimação, ou até uma subestimação, do problema, uma vez que a amostra representa cerca de $30 \%$ do corpo discente. Também é possível que tenham respondido ao questionário apenas aqueles que se sensibilizaram pelo tema. Além disso, foi observado que alunos do quinto e sexto ano, identificados como os maiores agressores, responderam bem menos ao questionário. O projeto QUARA preocupou-se em analisar qualquer tipo de agressão reportada, seja "uma vez um aluno gritou comigo", e até "eu fui vítima de estupro”. 


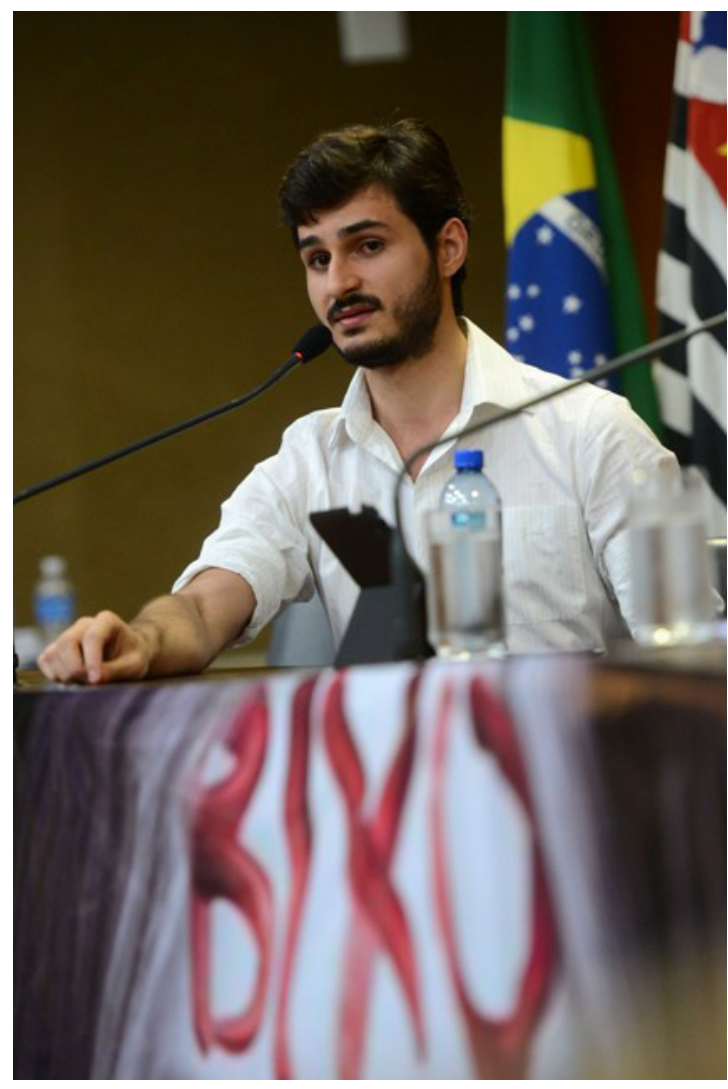

Felipe Scalisa depõe em audiência pública na ALESP em janeiro de 2015. Foto: Mauricio de Souza/ALESP

Para Fernanda, as consequências do ato violento para a vítima dependem do tipo de agressão, do grau e de como a pessoa lidou com a situação. Estudos mostram que podem ser associados quadros de depressão, transtornos de estresse pós-traumático, ansiedade, quadros fóbicos, doenças físicas crônicas, como quadros reumáticos, processos inflamatórios e doenças cardiovasculares. "A universidade é um espaço de acolhimento e formação, ser posto em uma situação de vulnerabilidade, dentro desse espaço, é difícil. Por isso, a importância de atuar preventivamente", afirma a professora. Além dos problemas pessoais, a vítima, principalmente a que denunciou, enfrenta problemas para se inserir no mercado. Márcia Couto diz "Muitas vezes também os alunos dizem: "eu destruí minha carreira, porque denunciei. Posso me formar, mas provavelmente não vou conseguir o trabalho que eu quero, a especialidade que eu quero".

\section{PARA ALÉM DO TROTE}

Os trotes não necessariamente acontecem na Semana de Recepção aos Calouros. Na Faculdade de Medicina, por exemplo, desde a morte do calouro Edison Tsung Chi Hsueh, em 1999, os trotes foram proibidos na primeira semana letiva. Todavia, casos de violência, agressões e humilhações acontecem com relativa frequência durante o primeiro ano e seguem até o final da graduação.

Infelizmente, muitas pessoas que sofrem violência não denunciam. A professora Márcia observa que há dois possíveis motivos para o silêncio nos casos de violência sexual, que a USP teve que enfrentar no último ano: o não reconhecimento do abuso sexual como violência, mas apenas como sexo não-consentido, e o silêncio advindo da culpabilização, muitas vezes pessoal, como se o fato de estar bêbada e/ou vestindo roupas "inadequadas" propiciasse a violência. Nesse caso, a condenação da vítima está inserida dentro da lógica machista, que ainda rege majoritariamente a sociedade contemporânea. Já Felipe Scalisa afirma que há forte pressão por parte dos colegas, que ameaçam as vítimas, a fim de proteger a reputação da instituição ou de uma festa. "Os veteranos ameaçam de suicídio social, deslegitimam, desmoralizam e dizem sempre ser 'uma frescura', como se fosse uma demonstração de fraqueza. Falam também que a menina que sofreu estupro é uma vagabunda, começam a inventar um monte de histórias sobre ela”, diz Felipe.

Outra questão fundamental é que o ato de denunciar envolve o autorreconhecimento. A tomada de consciência de que o ato sofrido foi uma violência e não um excesso é significativa e implica em uma série de consequências, que vão desde o julgamento dos colegas até o acolhimento institucional ou a falta dele. Para Maria Fernanda, muitas meninas não denunciam por não saberem como 


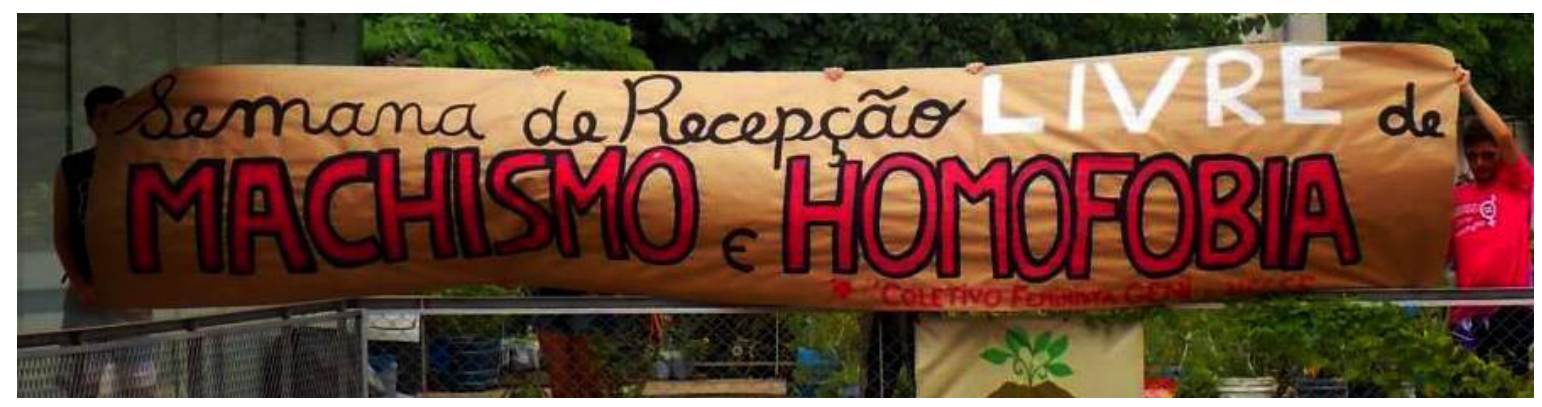

Faixa de recepção aos calouros do coletivo feminista Geni, criado na Faculdade de Medicina em 2014. Foto: Página do coletivo no Facebook

serão acolhidas em seus círculos sociais, pelo descrédito nas respostas que serão dadas dentro e fora da Universidade.

Para tentar dar fim à impunidade, vítimas de abusos sexuais e garotas solidárias à causa criaram, no final de 2013, o coletivo feminista Geni. As vítimas se organizaram no grupo e encontraram amparo e força para a publicização dos crimes, que resultaram na criação de uma Comissão Parlamentar de Inquérito (CPI) das Violações dos Direitos Humanos nas Faculdades Paulistas, na Assembleia Legislativa de São Paulo, em novembro do ano passado. Márcia Couto entende que "são nas reuniões do coletivo que as meninas caminham com o objetivo de fazer uma outra leitura, contra-hegemônica e não-tradicional, do que é a violência sexual que uma mulher sofre ou que pode vir a sofrer em um trote". Já a professora Maria Fernanda Tourinho reconhece que mesmo que o grupo ainda seja minoria dentro da faculdade, "elas fizeram um barulho significativo, tanto que hoje há uma CPI instalada por conta das denúncias”. Os coletivos tiveram grande repercussão e hoje são alvo de críticas, mas, na opinião da professora, a tendência é que a hostilidade enfraqueça, por ser um movimento dos alunos.

Os denunciantes também sofreram com a resistência e hostilização na Faculdade. Felipe, por exemplo, que foi um dos depoentes da audiência pública da ALESP, disse sofrer perseguição política desde então. "A faculdade virou um ambiente totalmente hostil para mim, eu não consigo andar no corredor, as pessoas trombam, ficam olhando. Sofri violência na sala de aula e também nas redes sociais, com pessoas indo na minha página para me ofender”. A situação levou Felipe à decisão de trancar o curso em 2015.

\section{A FORMAÇÃO DO MÉDICO}

O alto índice de violência registrado no curso de Medicina também pode estar associado a sua grade curricular. Na opinião de Scalisa, no currículo com viés majoritariamente biologiscista, faltam matérias voltadas para as ciências humanas no curso. Entretanto discute-se hoje a valorização do campo da humanização do ensino médico. Fundamental para a formação de um profissional sensível que respeite às diferenças, esta área pressupõe que o médico saiba reconhecer e respeitar o diferente, além de compreender que a assistência à saúde é um dos direitos humanos básicos. Para Maria Fernanda, "tudo isso precisa constituir um núcleo central da formação não só do médico, mas de todo profissional da saúde que lida com o outro, principalmente se este está numa posição de vulnerabilidade”

Na opinião da professora Márcia Couto, em faculdades como a FFLCH e a ECA, por exemplo, não há tolerância para esses tipos de violação, pois 
são cursos que dialogam cotidianamente com as questões humanas. "Muito me espantaria se houvesse denúncias de machismo, racismo ou homofobia nos trotes da FFLCH. Afinal, são cursos nos quais esses conteúdos já fazem parte da formação do aluno, que busca ser crítica sobre essas posições da sociedade", afirma.

\section{CALOURADA DIFERENTE}

Felipe Scalisa acredita que a Semana de Recepção dos Calouros, que acontece entre 23 e 27 de fevereiro, será diferente este ano, tendo em vista que a sociedade está com os olhos voltados para a faculdade. Aos novos alunos, diz "venham empoderados e não legitimem espaços de opressão. Não é a maioria que é agressora ativa, mas a maioria silencia e a maioria compactua. Existe uma cumplicidade muito grande em relação à violência, mas isso precisa mudar."

Nestes dias, os calouros estarão entrando pela primeira vez como alunos da famosa "Casa de Arnaldo”. Qual o sentimento que lhes ronda? Maria Fernanda entende que, por mais que tenha sido doloroso o momento da audiência publica e da instauração da CPI, eles foram importantes, porque a partir dele a mudança se estabeleceu. "A Universidade está atenta à situação e não vai tolerar a permissividade nas relações. Venham sem medo", diz.

GABRIELA SARMENTO graduanda em Jornalismo na Escola de Comunicações e Artes da Universidade de São Paulo (ECA-USP) e repórter da Revista de Cultura e Extensão USP - e-mail: gabrielasarmento11@gmail.com 